
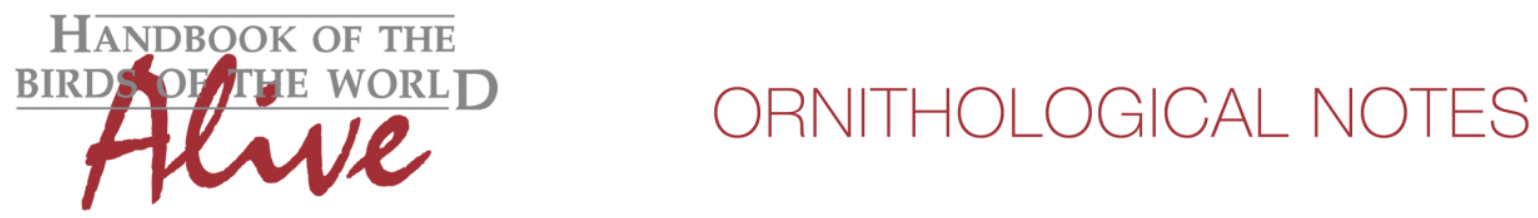

\title{
Notes on the vocalizations of Spot-backed Antbird (Hylophylax naevius)
}

Peter Boesman

In the following we briefly analyze and compare voice of the different races of Spot-backed Antbird (Hylophylax naevius). We also try to quantify the extent of any vocal differences using the criteria proposed by Tobias et al. (2010), as a support for taxonomic review. We have made use of sound recordings available on-line from Xeno Canto (XC).

If we compare loudsongs of all races, there are clearly two vocal groups, which are readily identified when e.g. looking at sonograms (Fig 1).
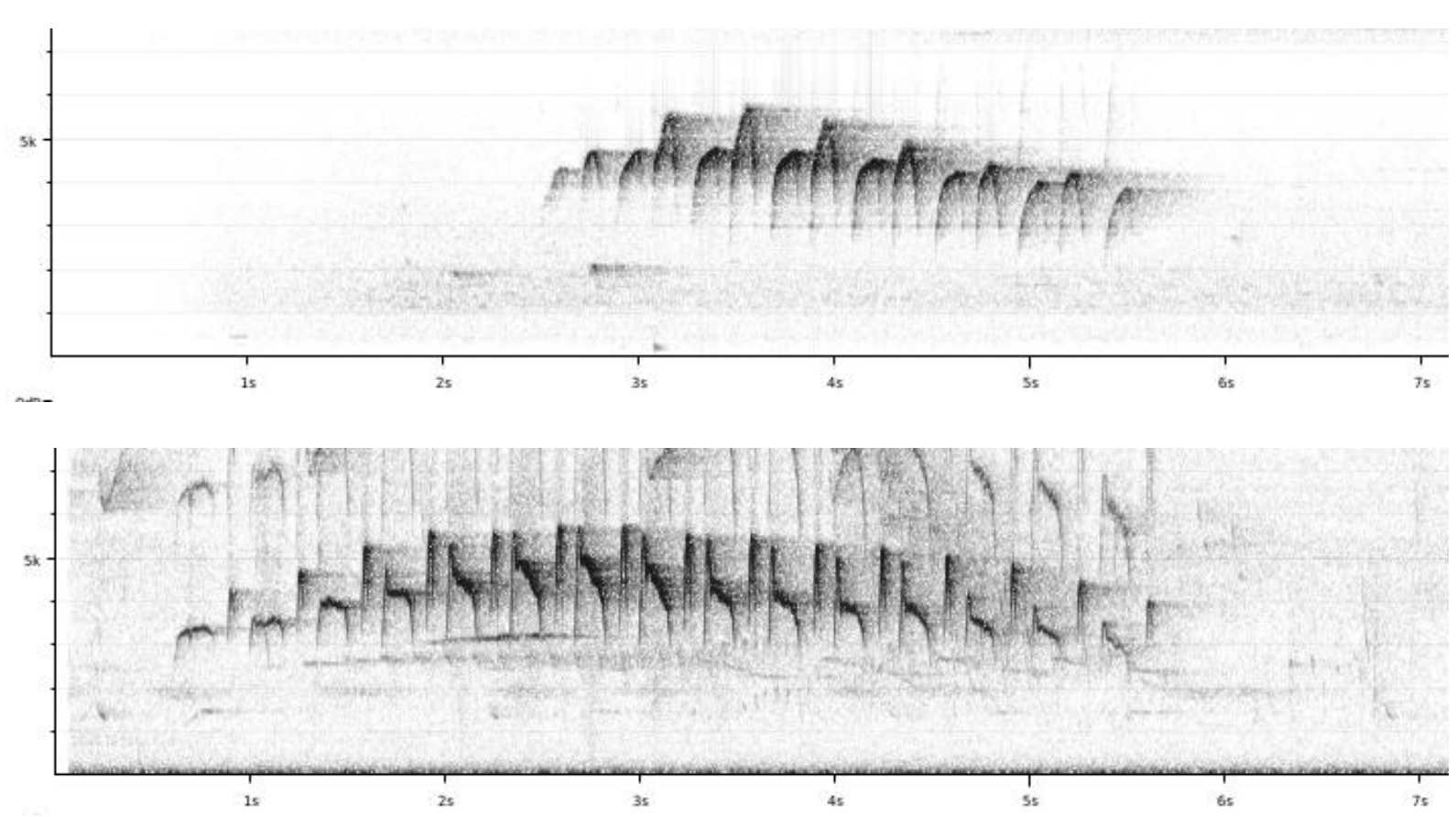

Figure 1: top to bottom: song with 'round' notes and song with 'spiky' notes

Loudsong of both groups is structurally similar: a rising/falling series of notes in groups of 2 notes, delivering a rather rhythmic song.

In one group, the repeated two notes are rounded, overslurred and of similar length, the second usually slightly shorter and higher-pitched (hereafter called 'mellow song').

In the other group, the two notes are very different, one is an extremely short spiky note and the second one is much longer, sharply downslurred with an initial frequency spike but then significantly lower-pitched, thus sounding quite different to the ear (hereafter called 'spiky song'). 


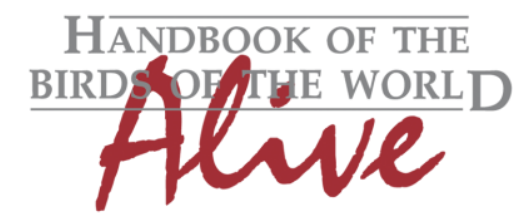

\section{ORNITHOLOGICAL NOTES}

The geographical distribution of these two vocal groups is quite peculiar.

The 'spiky song' occurs $S$ of the Amazon from the Belem area in the east throughout the Amazon region at least up to Rondônia in the west, and closer to the Amazon river it occurs west into NE Peru (the Loreto area), the furthest west being XC34664 around Borja (still in the lowlands) and XC249871 of extreme E Ecuadorian lowland.

The 'mellow song' occurs $\mathrm{N}$ of the Amazon in the Guianan and rio Negro region, and again in E Ecuador following the foothills south through Peru into Bolivia.

Scoring of vocal differences would probably give a figure of about 4-5 (based on e.g. shortest note length (2-3), note length ratio of note-pair (3), freq. range of single note,... which are significantly different for both groups).

Within the 'mellow song' group, there are also more subtle differences between birds from the foothills from $\mathrm{N}$ Ecuador to Bolivia and birds from the lowlands $\mathrm{N}$ of the Amazon river. The first subgroup has double notes in which the second note is clearly higher-pitched than the first note. The second subgroup has double notes in which the second note is lowerpitched than the first (at least towards the end of the song)(Fig. 2). Further analysis would be required to define scores.
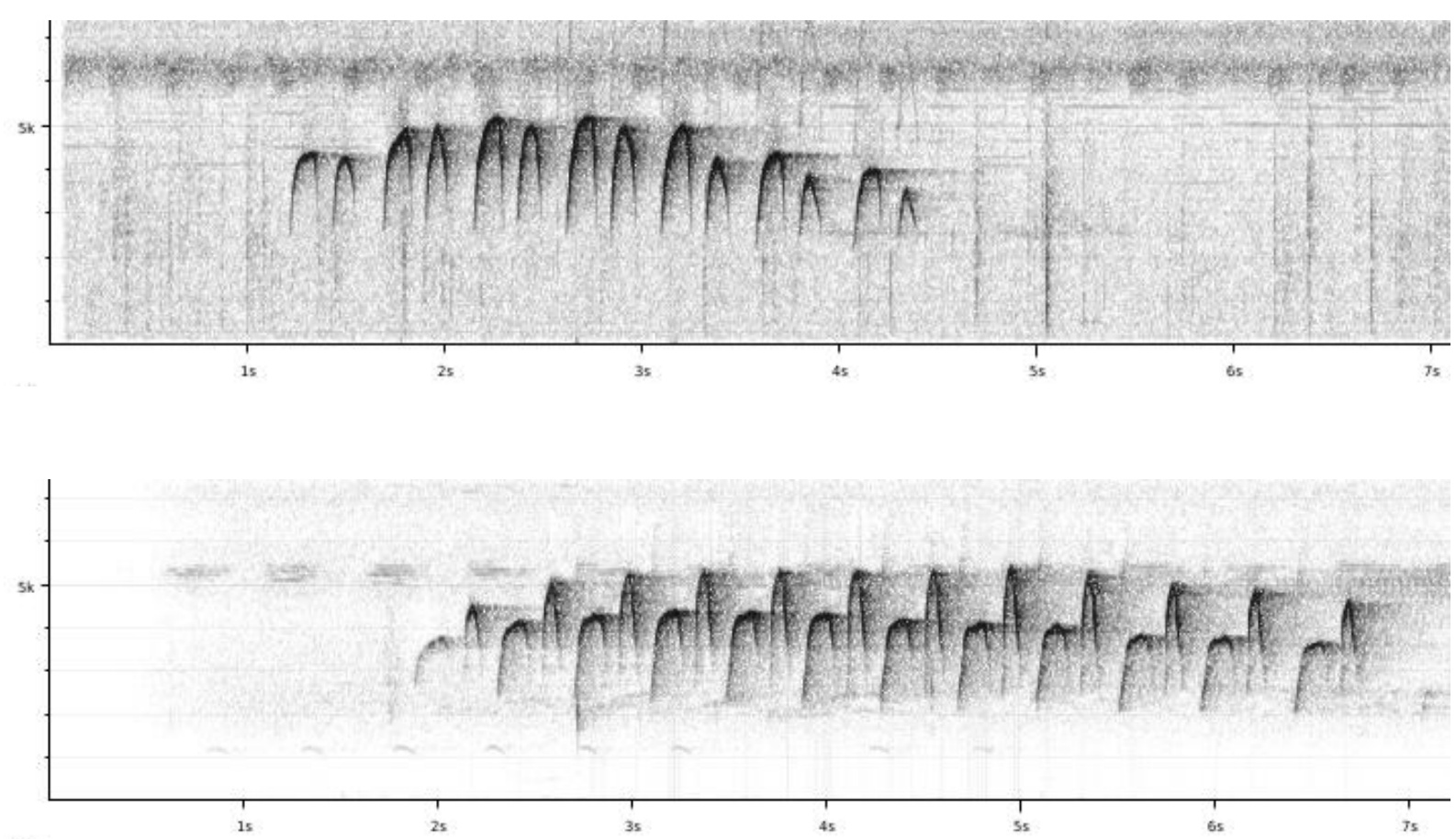

Figure 2: top to bottom: 'mellow song' from Venezuela and SE Peru. 

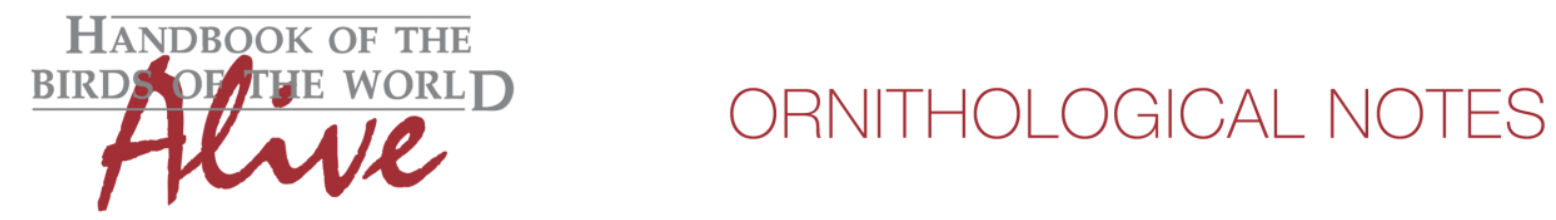

All in all, it would thus seem that vocally we can distinguish 3 groups, which show a clear geographical pattern (Fig. 3).

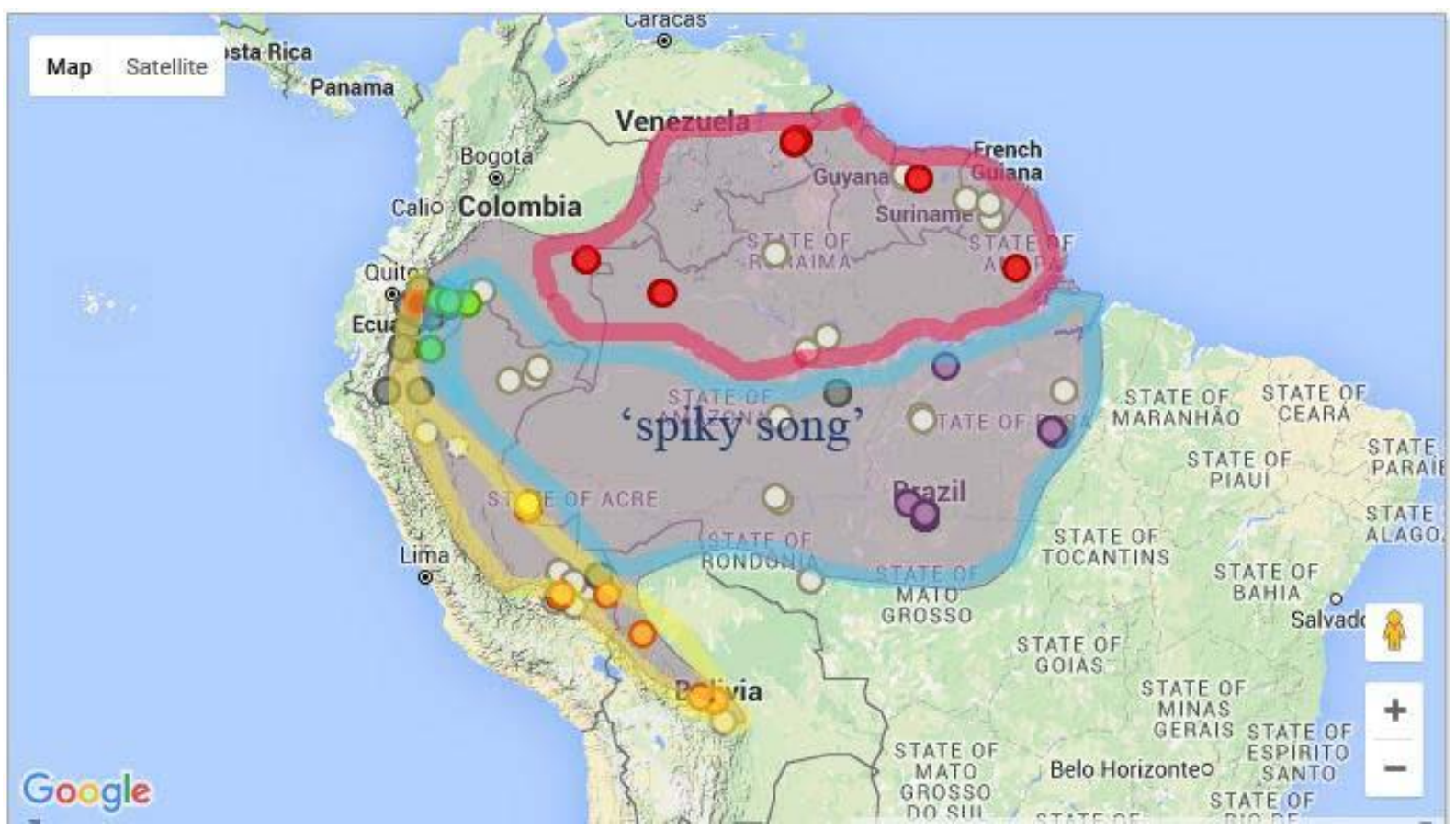

Figure 3: approximate geographical distribution of the 3 song types

These 3 groups more or less coincide with the following races:

group 1: Guianan and Rio Negro group: naevius and consobrinus

group 2: Amazonian group: theresae (in part), ochraceus

group 3: Andean foothill group: theresae (in part), peruvianus, inexpectatus

suggesting that race theresae may well represent 2 different taxa.

This note was finalized on 19th June 2015, using sound recordings available on-line at that moment. We would like to thank in particular the many sound recordists who placed their recordings for this species on XC.

\section{References}

Tobias, J.A., Seddon, N., Spottiswoode, C.N., Pilgrim, J.D., Fishpool, L.D.C. \& Collar, N.J. (2010). Quantitative criteria for species delimitation. Ibis 152(4): 724-746.

\section{Recommended citation}

Boesman, P. (2016). Notes on the vocalizations of Spot-backed Antbird (Hylophylax naevius). HBW Alive Ornithological Note 60. In: Handbook of the Birds of the World Alive. Lynx Edicions, Barcelona. (retrieved from http://www.hbw.com/node/931943 on 14 May 2016). 